The Board of Editors of Heredity have decided to publish invited reviews on topics particularly related to the subject interests of the Fournal. One review per volume will be published and that by $\mathrm{Dr}$ Cullis in the present issue represents the first of these.

Heredity (1977), 38 (2), 129-154.

\title{
MOLECULAR ASPECTS OF THE ENVIRONMENTAL INDUCTION OF HERITABLE CHANGES IN FLAX
}

\author{
C. A. CULLIS \\ John Innes Institute, Colney Lane, Norwich NR4 7UH
}

Received 14.x.76

\section{Contents}

Summary . . . . . . . . . . . . . 130

1. INTRODUCTION .

2. INDUGTION OF GHANGES IN FLAX . . . . . . . $\quad . \quad 130$

(i) Induction of plant weight differences . . . . . . . $\quad . \quad 132$

(ii) Induction of plant height differences . . . . . . . . $\quad . \quad 133$

(iii) Induction of nuclear DNA differences . . . . . . . . . . . 133

3. Reversion of INDUGed changes . . . . . . . . 134

4. Gharagterisation of DNA differences between genotrophs . 135

5. Ribosomal DNA differences betWeen different Genotrophs . 137

6. ISOZYME VARIATION BETWEEN GENOTROPHS . . . . . 138

(i) Peroxidase isozymes . . . . . . . . . . . . . . .

(ii) Esterase isozymes .

(iii) Acid phosphatase isozymes . . . . . . . . . . 140

7. INHERITANGE OF INDUGED CHARACTERS IN GROSSES BETWEEN GENOTROPHS AND BETWEEN GENOTROPHS AND OTHER Limum usitatissimum GENOTYPES . . . . . . . . . . . 140

(i) Crosses between L and S genotrophs . . . . . . . 140

(ii) Crosses of $\mathrm{Pl}$ with $\mathrm{L}$ and $\mathrm{S}$ genotrophs . . . . . . . 141

(iii) Crosses of L, S and $\mathrm{Pl}$ with other varieties . . . . . . 141

(iv) Inheritance of hairy capsule septa in genotrophs . . . . . . 142

8. Association of induced characters . . . . . . $\quad . \quad 143$

9. Possible meghanism of indugtion AND EXPRESSION OF INDUCED
GHANGeS

(i) Model for environmental induction of $D \dot{\mathcal{N} A}$ changes in flax . $\quad . \quad 147$

(ii) Control of expression of induced characters by DNA changes . . 149

10. Conclusion. . . . . . . . . . . . 151

11. Appendix . . . . . . . . . . . . .

12. REFERENCES . . . . . . . . . . . 152

$38 / 2-A$ 


\section{SUMMARY}

The conditions for the induction and stabilisation of environmentally induced changes in flax, and the characterisation of these changes for six characters have been reviewed. A model for the induction and expression of these changes has been proposed. The environmental conditions for the successful induction of heritable changes comprise at least two components; a specific inducing component, for example a particular fertiliser treatment, which is required to induce the change, and a general inducing component, providing for vigorous healthy growth, which is necessary for the induced changes to be inherited. Stable induced changes require appropriate environments for their maintenance, for example heated greenhouses for the first 5 weeks of seedling growth and adequate pot size. Under certain growth conditions the induced changes can themselves be modified. DNA differences induced in the different genotrophs can occur at a number of sites within the genome, including the ribosomal RNA cistrons. Environmental induction causes changes in the isozyme band patterns of peroxidase, acid phosphatase and esterase isozymes. The genotrophs behave as distinct genetic types in crosses, with a complcx pattern of inheritance of the hairy septa character. The association between the different induced characters is examined. All the genotrophs can be distinguished from each other on at least one of the six characters. A model for the induction of the DNA changes, involving a type of IS-element has been proposed. The expression of the induced changes, in terms of altered numbers of copies of particular sequences at specific sites within the genome, has been considered.

\section{Introduction}

THE interdependence of the genotype and of the environment in which it develops to give the observed phenotype has long been recognised, but the responses to environmental factors in one generation are not, as a rule, transmitted to subsequent generations. However, there are exceptions and specific environmental factors have been found to affect subsequent generations. For example stable changes have been induced in certain varieties of Linum usitatissimum (Durrant, 1958, 1962a, 1971) and in Nicotiana rustica (Hill, 1965). In the Linum usitatissimum varieties heritable changes were induced in a single generation by growth in a particular environment. These changes have remained stable, and of the same magnitude, over a large number of generations of plants grown in environments either the same as or different to the environment in which the changes were induced.

The purpose of this review is to consider the conditions required for the environmental induction of heritable changes in flax (Linum usitatissimum), the variation in the characters known to be susceptible to environmental induction and the relationship between these characters. A possible mechanism for the induction events and the expression of the induced changes will be discussed.

\section{Induction OF CHANGES IN FLAX}

Durrant $(1958,1962 a, 1971)$ found that heritable changes could be induced in the flax varieties "Stormont Cirrus" and "Lyrral Prince" by growth of plants of these varieties in different fertiliser combinations in the greenhouse and in the field. He found that when the progeny of treated plants were compared in the next generation under uniform conditions the progeny could vary in a number of characters, both the extent of the 
variation and the number of characters involved depended on the fertiliser treatments given to the parents (Durrant, 1958, 1962a, 1971). The changes transmitted to the first generation, could in some lines, be transmitted unchanged through a large number of generations (Durrant, 1958, 1962a, 1971).

Durrant initially followed the environmentally induced changes in terms of plant weight at maturity and described his induced lines in terms of this character. The plant weight of the progeny of the treated plants was found to vary widely, with the extremes being a large type, two to three times the weight of the original variety, and a small type, about half the weight of the original variety (Durrant, 1962a, 1971). The extreme types bred true under a number of growth conditions, including the inducing treatments given to the parental plants (Durrant, 1962a). Some of those of intermediate weight were still susceptible to the induction of changes by fertiliser treatments while other lines of intermediate weight were no longer susceptible to induction by fertiliser treatments (Durrant, 1962a). Thus after induction the derived lines could be classified into two classes; the *plastic type $(P l)$ of intermediate weight in which heritable changes could still be induced, and stable genotrophs, induced from $P l$, which bred true under a number of subsequent environmental conditions. (Durrant uses the term genotroph to include the plastic types. However in this review the tcrm genotroph will only be used to describe lines induced from the plastic type, which have lost the ability to respond to the fertiliser treatment. Wherever the term plastic $(P l)$ type is used, it will refer to the original variety from which the genotrophs have been derived.) The large stable genotroph $(L)$ and the small stable genotroph $(S)$ were the extreme types, in terms of plant weight, of the stable genotrophs induced from $P l$.

In addition to the plant weight differences, Durrant and his co-workers, and subsequently other workers, using seed of the genotrophs supplied by Durrant, have described a number of other characters which can be affected by the induction treatment. These characters are plant height (Durrant, $1962 a, 1971$ ), hairyness of capsule septa (Durrant and Nicholas, 1970; McLellan and Durrant, 1973), nuclear DNA amount (Evans, Durrant and Rees, 1966; Evans, 1968a), isozyme band pattern for peroxidase and esterase (Fieldes and Tyson, 1972, 1973a,b), and for peroxidase and acid phosphatase isozymes (Cullis and Kolodynska, 1975) and for ribosomal DNA amounts (Timmis and Ingle, 1973, 1975; Cullis, 1975, 1976).

The fertiliser treatments applied to the flax lines during induction experiments are detailed below (Durrant, 1962a).

$n-1.5$ per cent solution of ammonium sulphate added to compost to saturation at time of sowing, with subsequent watering and free drainage;

$p$-addition of 1.5 per cent solution of triple-superphosphate which had been left for 24 hours and the sediment removed.

$k$ - Potassium chloride added as a 1.5 per cent solution at sowing;

$g$-calcium hydrate mixed with the compost at the rate of one ounce to the cwt.

The compost to which the treatments were added was made of seven parts soil from the field, three parts Irish moss peat and two parts granite

* For a glossary of terms used see Appendix. 
chippings. A combination of letters denotes the addition of all those fertilisers. The fertilisers were added at sowing and again to the field plots where the plants were finally transplated. The actual combination of treatments used to induce changes are detailed in the sections dealing with the induction of specific changes.

\section{(i) Induction of plant weight differences}

The fertiliser treatments under which the plastic variety was grown included all combinations of $n, p, k$ and $g$. The seed was sown in boxes in a warm greenhouse (the temperature was not defined) where they received the solutions of fertilisers. After 5 weeks' growth in a heated greenhouse the young plants were transplanted to field plots, which had reveived the same fertilisers as the boxes. The progeny were grown in all combinations of $n, p, k$ and $g$. A range of values were obtained for the first generation, with the progeny of plants grown in any of the three treatments, $n p k g, n$ or $p k$ being the largest and those plants grown in $n k$ the smallest. These extreme types bred true in subsequent generations irrespective of the subsequent fertiliser treatments (Durrant, 1962a, 1971).

The intermediate types could be further subdivided into two groups, one in which the types were still susceptible to induction, and the other in which plasticity had been lost but no plant weight change had occurred. From now on these intermediate genotrophs will not be considered further.

Later experiments confirmed the effect on the plant weight of the progeny of treated plants of all the fertiliser combinations except that of $p$ (Durrant, 1962a). In these later experiments, the application of $p$ to the parental plants gave plants in subsequent generations that were as small as those obtained by the $n k$ treatment, where the $p$ treatment had previously given an intermediate plastic type. This change in the effect of the $p$ treatment has been explained by a change in the soil $p \mathrm{H} ; p$ at low $p \mathrm{H}$ produced a small type, while $p$ at moderate $p \mathrm{H}$ produced an intermediate plastic type (Durrant, 1962a, 1971). From this stage Durrant ignored the use of all combinations except $n$ to give a large type, $L$, and $p$ with low $p \mathrm{H}$ compost to give a small type, $S$.

In an attempt to define more precisely the induction conditions, the $P l$ variety was grown in culture solution, rather than in soil, with different levels of $n$ and $p$. Over a wide range of day/night temperatures in summer or winter, no induction was obtained by either an excess of $n$ or an excess of $p$. However a small type was induced by a régime of $19^{\circ} \mathrm{C}$ day $/ 11^{\circ} \mathrm{C}$ night temperature during winter, with either $n$ or $p$, although the same temperature régime during the summer was ineffective in producing any heritable changes (Durrant, 1962b, 1971). The parental plants grown in culture solutions were only about one-third the size of the plants grown in the field. The small genotroph induced by the $19^{\circ} \mathrm{C} / 11^{\circ} \mathrm{C}$ temperature was different to that induced by $p$ in the field (Durrant, 1971).

The induction of heritable changes by the treatments $n$ and $p$ was also attempted for plants grown in pots in a heated greenhouse. It was found that the fertiliser treatments $n$ and $p$ only produced genotrophs differing in weight by 10 per cent (as against up to six-fold for full induction) if the plants were grown in 5-inch pots in a heated greenhouse (Durrant and Jones, 1971). The treated plants in 5-inch pots were only about one-third 
the size of the field grown plants, and were about the same size as the plants grown in nutrient solutions described above. However, if the plants were grown in 7-inch pots throughout, then the full induction could be achieved. Thus there were different levels of induction which resulted in the production of genotrophs which have lost their plasticity but differ in plant weight from 10 per cent to 600 per cent depending on the combination of growth conditions provided.

\section{(ii) Induction of plant height differences}

Under virtually all growth conditions the $L$ genotroph is taller than the $S$ genotroph with the $P l$ type being taller than both (Durrant, 1962a). However in certain inductions this relationship does not hold. The small type induced by growth of plants under a particular temperature régime in culture solution was taller than that induced by $p$ in the field, and approximately the same height as the $L$ genotroph when all three lines were tested under the same conditions (Durrant, 1971).

In an induction experiment in 1961 (which will be referred to later as the " 1961 induction") $n$ and $p$ with low $p \mathrm{H}$ treatments were given to plants grown in a heated greenhouse for 6 weeks and then planted out into the field. The $n$ treatment gave a large genotroph (termed $L^{H}$ and referred to later) with approximately the same plant weight and height as the large genotrophs previously obtained. The $p$ treatment gave a small genotroph $\left(S^{h}\right)$ with approximately the same plant weight as the small genotrophs previously obtained, but $S^{h}$ was taller than the $S$ genotrophs previously obtained, and was approximately the same height as the $L$ genotrophs previously obtained (Durrant, personal comm.). This genotroph, $S^{h}$ differed in a number of characteristics from the other $S$ genotrophs obtained by $p$ treatment in other years (Durrant, personal comm. and see table 1 in Appendix). The $L^{H}$ and $S^{h}$ genotrophs produced in the 1961 induction experiment will be considered further later because they differed from the large and small genotrophs normally produced by the $n$ and $p$ treatments applied to the $P l$ type.

\section{(iii) Induction of nuclear $D \mathcal{N A}$ differences}

The nuclear DNA amounts of the genotrophs, as determined by Feulgen staining, were found to be different, with $L$ having 16 per cent more nuclear DNA than $S$ and $P l$ having an intermediate amount (Evans, Durrant and Rees, 1966; Evans, 1968a). During the first 5 weeks of growth of $P l$ in the appropriate inducing environments, $n$ and $p$, the nuclear DNA amounts of the two lines steadily diverged, with an increase in the $n$ treated line and a decrease in the $p$ treated line. After 5 weeks, the difference in the nuclear DNA amount between the $n$ and $p$ treated lines was the same as that found between $L$ and $S$ (Evans, Durrant and Rees, 1966; Evans, 1968a).

The nuclear DNA amount was also followed in the apical meristem cells of $P l$ plants which were grown in 5-inch pots with either the $n$ or $p$ treatment (when only small plant weight differences were observed in the following generation, see section 2 (i)). The nuclear DNA amount was found to diverge in the same manner, and to the same extent, as observed in experiments where the full induction occurred; that is, approximately 16 per cent 
difference was obtained after 5 weeks' growth. However when the seeds from plants, induced by $n$ and $p$ in 5-inch pots, were grown for 5 weeks in a heated greenhouse and then planted out in the field, only a 5 per cent DNA difference was observed in the progeny of the $n$ and $p$ treated plants. The second generation of plants again grown in the greenhouse and field showed no nuclear DNA differences (Durrant and Jones, 1971). Thus it would appear that the induction of the DNA differences was a two-stage process; first the increase or loss of DNA occurred, and then the change in DNA was stabilished. Since the first stage of the induction but not the second occurred when plants were grown with $n$ and $p$ treatments in 5-inch pots, there must have been different environmental requirements for these two stages (Durrant and Jones, 1971).

Even when the full plant weight differences were successfully induced, the DNA difference between the lines was not necessarily 16 per cent. In the 1961 induction, in which a taller $S$ was induced $\left(S^{h}\right)$, the nuclear DNA difference between the small, $S^{h}$, and the large, $L^{H}$, genotrophs induced at the same time was only 10 per cent (Durrant, personal comm.; Cullis, 1976). Thus genotrophs with a range of plant weights and nuclear DNA amounts can be produced.

On the basis of the information so far discussed it is clear that heritable changes were induced in the $P l$ type only if the fertiliser treatments were applied to $P l$ plants grown under suitable conditions. Durrant (1971) subdivided the inducing environment into two parts, the specific environmental component and the general environmental component. He defined the specific environmental component as the particular fertiliser or fertiliser combination, or other factor, which, with the general component, induced either $L$ or $S$. The general environmental component then comprised all environmental conditions other than the specific components. For example a general component comprised of growing plants in fertile soil with sufficient light for 6 weeks in a heated greenhouse and then the plants planted out in the field was appropriate for the induction of $L$ by the specific component of $n$ fertiliser treatment. The growth of plants in culture solutions under 16-hour day/8-hour night in winter was found to be the appropriate general component for the induction of $S$ by the specific component of a temperature régime $19^{\circ} \mathrm{C} / 11^{\circ} \mathrm{C}$ day/night temperature (Durrant, 1971). In this latter case the light intensity could equally have been considered as the specific component with the temperature régime as part of the general component. Therefore the environments in which heritable changes have been induced must be considered as a whole. The splitting of the factors into specific and general components is arbitrary as many environmental components have been shown to affect the number of characters, and the degree of the change in those characters, altered in the environmental induction.

\section{Reversion OF INDUGED GHANGES}

The plant weight and nuclear DNA differences of the $L$ and $S$ genotrophs were not stable in all subsequent environments. The plant weight and nuclear DNA amounts of $L$ and $S$ were stable provided they were grown for the first 6 weeks in a heated greenhouse. However, if $L$ and $S$ were grown from sowing to harvesting out-of-doors, then over three generations the nuclear DNA amounts converged; that of $L$ decreased while that of $S$ 
increased until they reached the same level at approxiniately the level of $P l$ (Joarder, Al-Saheal, Begum and Durrant, 1975). This decrease or increase could be halted at any stage by growing subsequent generations in a heated greenhouse for the first 5 weeks of growth. This arrested the change but did not reverse it (Joarder, et al., 1975). Through the period of nuclear DNA change there was no corresponding change in plant weight so that new genotrophs, termed nuclear DNA reversion lines, were obtained. Two of these nuclear reversion lines, $L_{3}$ and $S_{3}$ whose derivation is given in the Appendix, had the same nuclear DNA amounts, at the level of that found in $P l$, but still showed the full plant weight differences (Durrant and Jones, 1971; Joarder et al., 1975). The effect of growth totally out of doors on further generations is less well documented, but after six or seven generations the $L$ line (now genotroph $L_{6}$ or $L_{7}$ ) changed to a line with low plant weight and the nuclear DNA dropped to a level equal to that of a newly induced small genotroph (Durrant, personal comm.). Only specific reversion lines $L_{3}, L_{6}, S_{3}$ and $S_{6}$ will be considered further as examples of nuclear reversion lines: the other lines $L_{1}, L_{2}, L_{4}, L_{5}, S_{1}, S_{2}, S_{4}$ and $S_{5}$ will not be discussed.

A reversion of the nuclear DNA of $L$ and $S$ to the $P l$ level also occurred if the large and small genotrophs were grown in 5-inch pots in a heated greenhouse for a number of years. This situation again occurred with no change in the relative plant weights of the $L$ and $S$ genotrophs when grown in the field after 6 weeks in a heated greenhouse (Durrant, personal comm.)

Thus two types of environment for the growth of the genotrophs can be defined (Durrant, 1971):

(a) Stabilising environment-one in which particular plant weight and nuclear DNA amounts remain associated within the $L$ and $S$ genotrophs. This is an environment in which the plants are grown for the first 6 weeks in a heated greenhouse and then planted out in the field.

(b) Reversion or non-stabilising environments - growth conditions in which $L$ and $S$ genotrophs change in either nuclear DNA content, plant weight or both. Such an environment would be one in which plants are grown out of doors from sowing to harvesting.

\section{Characterisation of DNA differences Between genotrophs}

$L, S$ and $P l$ were shown to have different nuclear DNA amounts by Feulgen cytophotometry (Evans, Durrant and Rees, 1966; Evans, 1968a). $L$ had the highest nuclear DNA value, $S$ the lowest with $P l$ intermediate. The $L-S$ difference was 16 per cent while the $L-P l$ difference was 10 per cent of the DNA amount of $P l$. The DNA difference between large and small genotrophs from separate induction experiments varied; for example values of 10 per cent for the large-small difference were observed in the 1961 induction (Durrant, personal comm.; Cullis, 1976) and 19 per cent in another independent induction experiment (Durrant and Timmis, 1973). Thus there is no absolute value reached in the induction of DNA differences although there may be a maximum value for the possible induced change.

Flax has a diploid complement of 30 small chromosomes all about the same size so that if all the extra DNA was located on a single chromosome, or lost from a single chromosome, then there should be one or two noticeably different chromosomes when comparing $L$ and $S$. However in both cases, all the chromosomes appeared approximately the same size (Evans, 1968b). 
In autotetraploids of $L \times S$ more bivalents and fewer quadrivalents were found than in the autotetraploid parental lines (Evans, 1968b). From this result it was suggested that some of the chromosomes may have been structurally altered due to the DNA changes, causing a change in the ease of quadrivalent formation (Evans, 1968b). In these autotetraploids of hybrids between $L$ and $S$, it is still not possible to distinguish the respective parental chromosomes so that the DNA changes are likely to have been spread over a number of chromosomes, with relatively small changes in each.

The DNA from $L, S$ and $P l$ genotrophs has been characterised in some detail (Cullis, 1973, 1975; Timmis and Ingle, 1973, 1974), by caesium chloride density gradient analysis, thermal denaturation and by renaturation experiments.

The DNA from all three genotrophs contains three bands in equilibrium neutral caesium chloride gradients; a main band with density $1.698 \mathrm{gcm}^{-3}$, a light satellite with density $1.688 \mathrm{gcm}^{-3}$ and a heavy shoulder with a density $1.710 \mathrm{gcm}^{-3}$ (Ingle, Pearson and Sinclair, 1973; Cullis, 1973, 1975; Timmis and Ingle, 1973). There was no difference detected between the proportions of the different bands in the three genotrophs, with the light satellite comprising about 17 per cent of the total DNA. Thus all the DNA differences could not have been located in the light satellite fraction, or this would have a markedly altered proportion in the different lines.

The DNAs from $L$ and $S$ were compared by the differentiation of their thermal denaturation profiles (Timmis and Ingle, 1974) which provides more detailed information about the distribution of base sequence heterogeneity within the DNA than is obtained with neutral caseium chloride density gradients. A number of different components were observed but no significant differences were found between the DNAs from $L$ and $S$. The extra DNA in $L$, compared with $S$, must therefore have approximately the same range of heterogeneity of base composition as the total DNA in both genotrophs.

More detailed information about the DNA sequences can be obtained by renaturation experiments, in which single-stranded DNA is allowed to form double stranded regions under the appropriate conditions. The rate of formation of double stranded regions, which depends on the incubation conditions, is a measure of the number of copies of a particular sequence that is present in that DNA (Britten and Kohne, 1968). The kinetics of renaturation of the DNAs from $L, S$ and $P l$ have been determined under a number of conditions (Cullis, 1973, 1975; Timmis and Ingle, 1974). The renaturation kinetics of the DNA from $S$ and $P l$ were indistinguishable. The reaction appeared to be biphasic with a fast renaturing portion (the sequences with a high degree of repetition within the genome) forming approximately 29 per cent of the total DNA, while the slow renaturing portion (the sequences present only once in the genome) forming the other 71 per cent of the total DNA (Cullis, 1975).

The renaturation kinetics of DNA from the $L$ genotroph showed differences to that from $S$ and $P l$. In DNA from $L$, the fast renaturing portion (which appeared to renature at a similar rate to the fast portion in $S$ and $P l$ ) only formed about 24 per cent of the total DNA, while the slow renaturing sequences formed about 62 per cent of the total. The remainder of the DNA from $L$ renatured with a rate intermediate between the fast and slow fractions 
which indicated that the degree of repetition of those sequences was intermediate between that of the repetitive and unique sequences (Cullis, 1973, 1975). This intermediate fraction contained sufficient DNA to account for virtually all the DNA difference between $L$ and $S$. However, since the difference in nuclear DNA amounts between $L$ and $P l$ was smaller than that between $L$ and $S$, the DNA in the intermediate fraction was more than could account for the DNA differences betwen $L$ and $P l$. To explain the observed renaturation curves the following hypothesis has been proposed (Cullis, 1975). The change in nuclear DNA content in the induction of $S$ from $P l$ involves the loss of some repeated and some unique sequences leaving the overall proportions of repeated and unique sequences unaltered. The change in nuclear DNA content in the induction of $L$ from $P l$ involves two processes; the loss of certain sequences, possibly the same sequences as those lost in the induction of $S$ from $P l$, and the gain of the intermediate repetitive fraction. It was suggested that the intermediate fraction could only have arisen from an increase in the number of copies of a certain portion of the unique sequences. To account for the difference in renaturation rates between the intermediate and unique sequences, the enrichment of the intermediate fraction would have to have been approximately 70 -fold, that is, the intermediate sequences are present as approximately 70 copies in $L$, but only as one in $\mathrm{Pl}$. It should be possible to isolate the intermediate fraction of DNA from $L$ and use this to determine directly the relative amounts of these sequences in $P l$ and the other genotrophs.

$L$ and $S$ are not plastic and it has been shown that a nuclear factor was required for the maintenance of plasticity (Durrant and Timmis, 1973). Thus part of the postulated lost DNA in both $L$ and $S$ on induction from $P l$ may have been responsible for the maintenance of plasticity. Further speculation on these lines really requires a more detailed knowledge of the sequences actually present, or absent, in $L, S$ and $P l$.

A comparison of the sequences present in the nuclear reversion types would provide information as to whether this was a true reversion, that is, whether the sequences changing when the lines revert were the same as the sequences involved in the original induction. If the sequences involved in the reversion were different to those involved in the original induction, then the reversion would be equivalent to a further induction event, rather than a destabilisation of the original induction. This is being investigated in this laboratory.

\section{Ribosomal DNA differences between different genotrophs}

The number of ribosomal RNA cistrons per genome of a number of flax genotrophs has been determined (Timmis and Ingle, 1973, 1975; Cullis, $1975,1976)$. It was found that the $P l$ type, $L, L_{3}$ and $L^{H}$ all had approximately 2500 cistrons per diploid genome although the value for $P l$ was slightly higher than the other lines. This difference was not significant (Cullis, 1976). $S, S_{3}, S_{6}$ and $S^{h}$ all had approximately 1600 cistrons while $L_{6}$ only had 1050 cistrons per diploid genome (Cullis, 1976). $L, L_{3}$ and $L^{H}$ were all phenotypically large in plant weight. $L_{3}$ and $L_{6}$ were derived from $L, S_{\mathbf{3}}$ and $S_{6}$ were derived from $S$ while $L^{H}$ and $S^{h}$ were an independent induction of large and small genotrophs. All the low plant weight genotrophs had a reduced level of ribosomal cistrons but this reduction was not 
to the same value in all cases. The association between ribosomal cistron number and plant weight will be considered later (see section 8).

Thus there would appear to be no change, or possibly a slight reduction in the ribosomal cistron number on the induction of the large genotroph from $P l$, and no change in the nuclear reversion line $L_{3}$, where the DNA fell to the $P l$ level. A reduction in the cistron number of 60 per cent of the cistrons in $P l$ was associated with the induction of $S$ from $P l$, but no further change was involved in the nuclear reversion lines $S_{3}$ and $S_{6}$ where the nuclear DNA rose to the $P l$ level and then fell to the $S$ level respectively. In the line $L_{6}$, which was derived from $L_{3}$, the nuclear DNA level had fallen to the same value as that found in $S$ and the ribosomal cistron number had fallen to 40 per cent of the number in $L_{3}$ (Cullis, 1976). This value for the ribosomal cistron number in $L_{6}$ was only two-thirds that found in $S$.

\section{ISOZYME VARIATION BETWEEN GENOTROPHS}

$L$ and $S$ resemble oil-seed and fibre varieties of $L$. usitatissimum respectively with $L$ having a much greater degree of basal branching. Peroxidase has been studied because of its involvement in the oxidase system concerned with the level of indole acetic acid (IAA) within plant tissues (Galston, Bonner and Baker, 1953), and IAA may be involved in the differences in the degree of basal branching observed between the genotrophs $L$ and $S$. In addition to the peroxidase system, two other general enzyme systems, the esterases and acid phosphatases, have been studied (Fields and Tyson, 1972, 1973a, b; Cullis and Kolodynska, 1975).

\section{(i) Peroxidase isozymes}

A large number of peroxidase isozymes can be separated by polyacrylamide gel electrophoresis. Fieldes and Tyson (1972) showed that there were four anionic peroxidase isozymes in extracts from $L$ and $S$ stems. Cullis and Kolodynska (1975) showed that, in addition to these, there were various numbers of cationic peroxidase isozymes in stems from $L$ and $S$ and five cationic and five anionic peroxidases from stems in $P l$. There were also found to be 12 peroxidase isozymes in roots from $L$ and $P l$ and 10 peroxidase isozymes in roots from $S$ (Cullis and Kolodynska, 1975). The total band patterns are shown in fig. 1 .

The band pattern for $P l$ stems contains the sum of the bands found in $L$ and $S$ although the activities of the various bands differed in the different types. From these data it was suggested that the band patterns of $L$ and $S$ could be produced by differential regulation of the peroxidase isozymes, since $P l$ had the capacity to form all the bands, rather than by the modification of particular isozymes to change their relative mobilities (Cullis and Kolodynska, 1975).

In the root system, bands appeared in $S$ which were not found in either $L$ or $P l$ (the latter two having the samc isozyme band pattern) so that thesc must have been formed either by the expression of genes not expressed in $P l$ in the environment in which these plants were grown, or by the modification of the isozymes found in $L$ and $P l$. Fieldes and Tyson (1972) and Fieldes, Tyson and Bashour (1976) found that the relative mobility of the stem peroxidases of the $L$ and $S$ genotrophs could be modified by the environment 
in which the plants were grown, and that the relative mobilities could also be modified during development. Thus it would appear that differential regulation and modification of pre-existing peroxidase isozymes could be associated with the induction of the flax genotrophs.

The nuclear reversion lines were tested for their isozyme band patterns (Fieldes and Tyson, 1973b; Gullis and Kolodynska, 1975). If the genotrophs were classified according to plant height rather than plant weight, then the

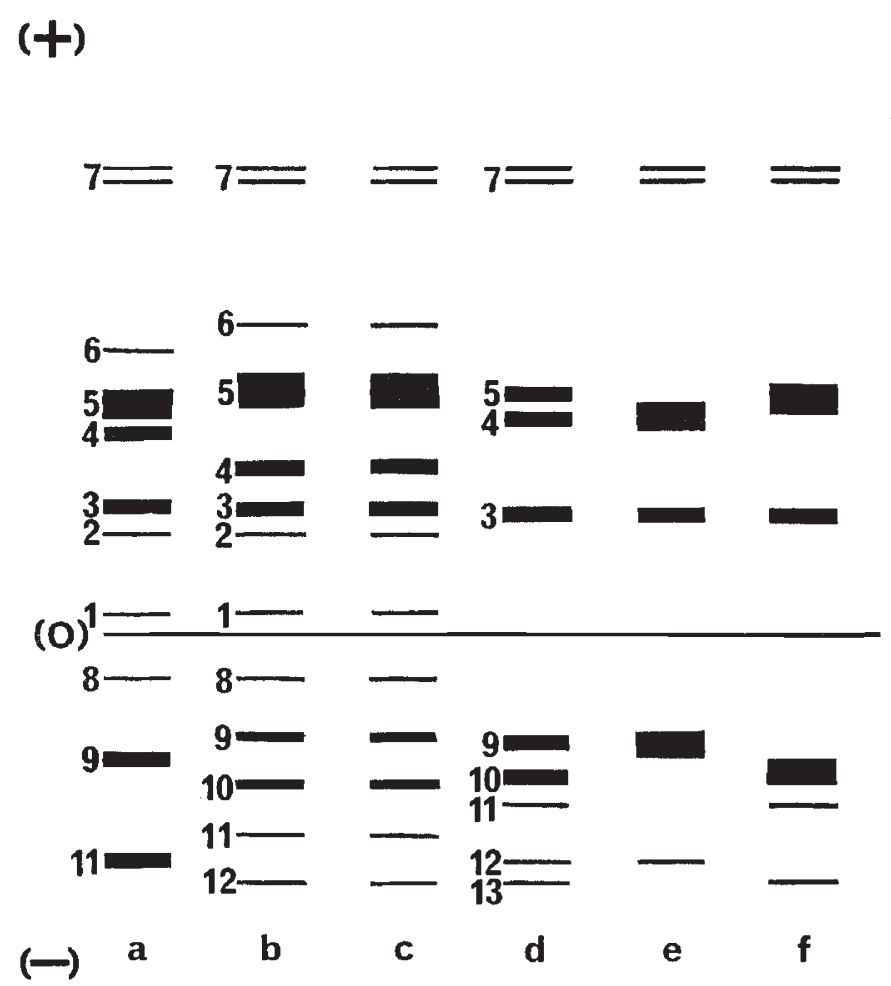

FIG. 1.-Isozyme band pattern for peroxidase from $L, S$ and $P l$ genotrophs from roots and stems. a $-S$ roots, $\mathrm{b}--L$ roots, $\mathrm{c}-P l$ roots, $\mathrm{d}-P l$ stem, $\mathrm{e}-S$ stem, $\mathrm{f}-L$ stem.

isozyme band patterns were the same for all members of a particular group. Thus the group $L_{3}, L^{H}, S^{h}$ were all approximately the same height and had the same isozyme band pattern as $L$. The other group contained $S_{3}, S_{6}$ and $L_{6}$ which were all short and had the same isozyme band pattern as $S$.

The peroxidase activity in $S$ was found to be greater than that in $L$ (Fieldes and Tyson, 1973a). This was true both for the gross peroxidase activity per unit fresh weight and for the specific activity. The activity of each of the four anionic peroxidases from stems was found to be higher in $S$ than in $\mathrm{L}$.

\section{(ii) Esterase isozymes}

Small mobility differences were found between the three main esterase bands found in stems of $L$ and $S$ (Fieldes and Tyson, 1973a), the mobilities 
of the $S$ isozymes being lower than those in $L$. The $P l$ type was not examined. No differences were found in the mobilities of the esterase isozymes from developing roots of $L, S$ and $\mathrm{Pl}$ (Cullis and Kolodynska, 1975). The isozyme activities were higher in $L$ than in $S$ (Fieldes and Tyson, 1973a). The mobilities of the isozymes in the $\mathrm{F} 1$ of $L \times S$ were found to be intermediate between the parental values (Fieldes and Tyson, 1973b).

\section{(iii) Acid phosphatase isozymes}

Three acid phosphatase isozyme bands from the roots of $S$ and $P l$ and four bands from the roots of $L$ have been described (Cullis and Kolodynska, 1975). The fastest running band of all three lines had the same mobility. The other two bands in $P l$ corresponded to two of the bands in $L$ while the mobilities of the bands in $S$ were lower than those in $L$ and $P l$ (Cullis and Kolodynska, 1975).

In all three enzyme systems, thc mobilities of those isozymes of $S$, which were different to those found in $L$ and $P l$, were lower than the mobilities of the corresponding (or nearest) isozyme in the other two lines. It is clear that particular isozyme band mobilities can be affected by the environment in which the plants are grown. The differences observed can be duc to both the production of different isozymes and the differential modification of the same isozyme in different genotypes.

7. INHERITANCE OF INDUCED CHARACTERS IN CROSSES BETWEEN GENOTROPHS AND BETWEEN GENOTROPHS AND OTHER Linum usitatissimum GENOTYPES

\section{(i) Crosses between $\mathrm{L}$ and $\mathrm{S}$ genotrophs}

In the F1 of either $L \times S$ or $S \times L$ there is an immediate breakdown of stability and a range of plant weights are found. In the F2 there is a positive correlation between the weights of the F1 plants and the F2 family means (Durrant, 1962b; Durrant and Tyson, 1964). There is an increase in variation in plant weight in the F1 and F2 with the variation in $S \times L$ being greater than in $L \times S$, and both being greater than the parental variation (Durrent and Tyson, 1964). However, other than this incrcased variation in the F1s and F2s, $L$ and $S$ behave as distinct genetic types (Durrant and Tyson, 1964).

In summer in the field, the weight of $L$ is larger than $P l$ which is larger than $S$, with the mean $F 1$ and F2 weights of $L \times S$ and $S \times L$ similar to $P l$. In winter conditions, in a heated greenhouse, $P l$ weight is greater than either $L$ or $S$, the latter two being approximately equal, and again the F1 and F2 weights of $L \times S$ and $S \times L$ are similar to $P l$ (Durrant, 1971).

$P l$ is taller than $L$ which is taller than $S$ in both summer and winter conditions but both the F1 and the F2 plant height of $L \times S$ and $S \times L$ are the same as $L$ (Durrant, 1971).

In crosses between $L$ and $S$, the $L$ pattern was dominant for the anionic peroxidase band mobilities for stem extracts, and this dominance was found to extend into the $\mathrm{F} 2$; that is there is no segregation of the $L$ and $S$ band patterns in the F2 (Fieldes, Tyson and Bashour, 1976).

A dominance of the $L$ genotroph pattern for anionic and cationic peroxidase and acid phosphatasc isozymes in the F1 of $L \times S$ and $S \times L$ has 
been found in this laboratory (Cullis, unpublished). However segregation was found in the F2 of both $L \times S$ and $S \times L$ for peroxidase and acid phosphatase isozymes; a 3.1: 1 ratio for $L$ peroxidase pattern to $S$ peroxidase pattern was obtained from the F2 plants (Cullis, unpublished). The acid phosphatase isozyme band pattern did not always segregate with the peroxidase isozyme band pattern, that is some of the F2 plants showed an $L$ peroxidase band pattern and an $S$ acid phosphatase band pattern (Cullis, unpublished).

\section{(ii) Crosses of $\mathrm{Pl}$ with $\mathrm{L}$ and $\mathrm{S}$ genotrophs}

The environment in which these crosses were carried out is important since changes could have been induced in $P l$ by the environment in which the $P l$ plants used as parents, were grown. When $P l$, growing in a noninducing environment, was used as the female parent in crosses with $L$ and $S$, growing in inducing environments, permanent changes occurred in the Fl, and these changes were transmitted (Durrant, 1971). The changes involved both the plant weight and the hairy capsule septa character. This happened even though there was no permanent change in $L$ and $S$ in these environments. Thus, although $L$ and $S$ were stable, growth under inducing conditions may have caused transient changes which could be stabilised and were heritable when these genotrophs were used as parents in crosses with $P l$ grown under non-inducing conditions (Durrant, 1971). If $L$ and $S$ were grown under non-inducing conditions then no heritable changes were induced when they were crossed to $P l$, also grown under non-inducing conditions.

\section{(iii) Crosses of $\mathrm{L}, \mathrm{S}$ and $\mathrm{Pl}$ with other varieties}

The genotrophs $L$ and $S$ and the original $(P l)$ type of Stormont Cirrus have been crossed with other flax and linseed varieties which did not show the ability to undergo heritable changes in response to the fertiliser treatments used to induce changes in Stormont Cirrus (Durrant and Tyson, 1964; Durrant, 1972; Durrant and Timmis, 1973). When crossed with $L$ and $S$, other flax and linseed varieties could be divided into two groups based on their effect on the plant weight of the progeny (Durrant, 1972). Two varieties, Royal (a linseed variety) and Hollandia (a flax variety) showed no dominance for plant weight. If high plant weight and low plant weight selections were made for $L \times$ Royal and $S \times$ Royal (or their reciprocals, as there was no difference between reciprocal crosses) then lines were obtained in which the difference in plant weight of $L \times$ Royal $-S \times$ Royal was greater than the original difference between $L$ and $S$ (Durrant, 1972). Since selection for high and low plant weight lines was ineffective in $L$ and $S$, there must have been interaction between the genomes of the genotrophs and Royal. Whether this interaction was either a destabilisation similar to that observed in crosses between $L$ and $S$ or evidence for plasticity in the crosses could not be determined. The other four varieties tested, three flax types and one linseed type, all showed dominance for plant weight in the F1 (Durrant, 1972).

Crosses were made between Royal, which is a non-plastic variety, and $P l$ to find evidence for genetic factors determining plasticity (Durrant and Timmis, 1973). The reciprocal crosses $P l \times$ Royal and Royal $\times P l$ showed 
differences, in that $P l \times$ Royal was still plastic while Royal $\times P l$ was not plastic, as determined by the ability to change the nuclear DNA amount in response to $n$ and $p$ treatments. $\mathrm{Up}$ to four backcrosses were made to each parent and it was found that neither Royal $\times P l^{5}$ nor $P l \times$ Royal $^{5}$ were plastic although the former had 97 per cent of its nuclear DNA derived from the $P l$ line. In the case of $P l \times$ Royal $^{5}$, since $P l \times$ Royal is plastic, an increase in the proportion of the nuclear DNA derived from Royal has caused a loss of the plasticity. Thus it would appear that both nuclear and cytoplasmic factors were necessary for $P l$ to show plasticity and possibly that the nuclear factor was necessary for the maintenance of the cytoplasmic factor, but cannot synthesise it de novo (Durrant and Timmis, 1973). Although the $P l$ and Royal lines appeared unchanged during the time the above crosses were performed, the possibility of heritable changes being transmitted through Royal cannot be ruled out.

The progeny in the first generation of $P l \times$ Royal can be induced to show the same nuclear DNA differences as those that can be induced in $P l$, but $P l \times$ Royal $^{2}$ can only be induced to 80 per cent of this value. This raises two possibilities; either that the $P l$ genome in the hybrid $P l \times$ Royal can be induced to increase its DNA at susceptible loci to twice the value normally achieved in $P l$, or that Royal has sites in the genome susceptible to environmental induction of an incrcase or a decrease in DNA. Since the $P l \times$ Royal $^{2}$ is still susceptible to induction to a level of 80 per cent of that of $P l$, in this case the $P l$ genome would have to be increasing more than three times as much as occurs in the normal $P l$ lines. Thus it is likely that the Royal genome has sites susceptible to environmentally induced DNA changes (Durrant and Timmis, 1973), but is unable to respond to the specific inducing component effective in the induction of genotrophs from Stormont Cirrus.

\section{(iv) Inherilance of hairy capsule septa in genotrophs}

Hairs on the false septa of capsules and hairless septa have been reported in Linum (Tammes, 1928; Dillman, 1936). The hairy condition was reported to be dominant to the hairless and in the $\mathrm{F} 2$ of a cross between hairy and hairless types, ratios of approximately 3 hairy to 1 hairless were obtained (Tammes, 1928). However in one cross a ratio of approximately $15: 1$ was obtained (Tammes, 1928). On the basis of these results it was suggested that the hairy character was probably controlled by a single factor. This factor has been designated as the gene $H$ - $h$ (controlling hairy-hairless septa) in Stormont Cirrus (Durrant and Nicholas, 1970). However, in crosses between hairy and hairless genotrophs, dominance was not complete in the $\mathrm{F} 1$, the segregation in the F2 was not $3: 1$, hairy to hairless, and the hair number per septum in heterozygotes could be separated into distinct classes (Durrant and Nicholas, 1970; McLellan and Durrant, 1973). Thus the expression of the hairy capsule septa character need not be determined by a single factor and the $H$ - $h$ notation has not been used in this review.

$S$ and $P l$ had hairs on the false septa while $L$ had none. Not all inductions of $L$ and $S$ showed the same relationship between plant weight of the genotroph and the hairyness of the septa; in the 1961 induction experiment an $L$ genotroph with hairy septa and an $S$ genotroph with hairless septa were produced and these will be considered further later. 
In crosses between $L$ and either $S$ or $P l$ most of the Fl plants had hairy septa, with fewer hairs than the homozygotes (the level in the Fl was approximately half that found in the hairy parents) (Durrant and Nicholas, 1970; McLellan and Durrant, 1973). There were a number of Fl plants in $L \times S, P l \times L$ and $L \times P l$ which were hairless. In the F2 a number of classes of plants could be distinguished. One class of plants contained those which were hairless and so resembled the $L$ parent in the original cross. The plants with hairy septa could further be divided into four classes, these with about 60 hairs per septum, which was the same as the number found in $P l$ and $S$, and three classes of intermediate hair number, with approximately 30 (class I), 40 (class II) and 50 (class III) hairs per septum. It has been suggested that the latter three classes were heterozygous for the locus controlling hairyness with different levels of activity producing the different classes (Durrant and Nicholas, 1970; McLellan and Durrant, 1973).

In the F2 of $L \times P l, L \times S$ and $P l \times L$, there was an excess of hairless types compared with the other classes (Durrant and Nicholas, 1970). If class III was selected in the F2, then the F3 from these plants gave an excess of hairy types with 60 hairs per septum while class I and class II gave ratios not significantly different to $3: 1$ hairy : hairless, in the F3. In the F3 of $L \times S$ and $S \times L$ a further proportion of heterozygotes gave a disproportionate number of progeny with 60 hairs per septum, but this was not observed in the F3 of $L \times P l$ and $P l \times L$, nor in subsequent generations of any of the crosses.

Hairyness of capsule septa was normally stable in the genotrophs but in some combinations of genetic background and environment it became unstable. There were rare and sporadic changes in $L$ (producing plants with hairy septa) and in $S$ (producing plants with hairless septa) themselves. From the appearance of excess hairless plants in the Fl of crosses between $L$ and either $S$ or $P l$ it was suggested that there was a potential for a hairy to hairless change (McLellan and Durrant, 1973). The selection of class III heterozygotes in the $\mathrm{Fl}$ also selected for a potential hairless to hairy change in the F2s (McLellan and Durrant, 1973). The instability of the hairy locus in the Fl is similar to the instability of plant weight in the Fl of $S \times L$ and $L \times S$, so a number of properties may be destabilised in the combination of the two induced genomes.

\section{Association of induced characters}

The characters so far described which have been shown to vary during the environmental induction of genotrophs are final plant weight, plant height, nuclear DNA content, number of hairs on the false septa of capsules, isozyme band pattern and ribosomal RNA cistron number. The value for each of these characters for the lines considered in this review is given in table 1. In addition to these six characters, the association between plant weight and hairy capsule septa and flower colour (a white-flowered mutant had been obtained by irradiation, denoted $w$ for white, $W$ for blue flowers) has also been investigated (Durrant, 1974).

The original induction of the extreme types gave: (i) a large genotroph $L$, which was intermediate in height, had a high nuclear DNA content, hairless capsule septa, and approximately 2500 ribosomal RNA cistrons (Durrant, 
1962a, 1974; Evans, 1968a; Durrant and Nicholas, 1970; Cullis, 1976), and (ii) a small genotroph, $S$, which was shorter than both $L$ and $P l$, had a low nuclear DNA content, hairy capsule septa and approximately 1600 ribosomal RNA cistrons (see table 1). However in a later induction a large genotroph $L^{H}$ was obtained, which was taller than $L$, had hairy septa, a lower nuclear DNA content than $L$, and approximately 2500 ribosomal RNA cistrons. In the same year a small genotroph, $S^{h}$, was obtained which had an intermediate height, the same nculear DNA content as $S$, hairless septa and approximately 1600 ribosomal RNA cistrons. Thus these two induction experiments show that plant weight, height and capsule septa hair number

TABLE 1

Summary of various characteristics of the original variety and the eight genotrophs described in this review

Key: Peroxidase isozyme patterns- $P l$ (as found in plastic geno.). $L$ (as found in $L$ geno.), $S$ (as found in $S$ geno.).

\begin{tabular}{|c|c|c|c|c|c|c|}
\hline \multirow[b]{2}{*}{ Genotroph } & \multicolumn{6}{|c|}{ Character } \\
\hline & Plant weight & Plant height & $\begin{array}{c}\text { Capsule } \\
\text { septa }\end{array}$ & $\begin{array}{c}\text { Nuclear DNA } \\
\text { content(d) } \\
(\mathrm{pg})\end{array}$ & $\begin{array}{c}\text { rRNA } \\
\text { cistron } \\
\text { number }^{(d)(e)}\end{array}$ & $\begin{array}{c}\text { Peroxidase } \\
\text { isozyme band } \\
\text { pattern } \\
\end{array}$ \\
\hline$P l$ & Intermediate ${ }^{(a)}$ & Tall(a) & Hairy $^{(c)}$ & $1 \cdot 40$ & 2660 & $P l$ \\
\hline$L$ & $\operatorname{High}^{(a)}$ & Intermediate ${ }^{(a)}$ & Hairless ${ }^{(c)}$ & 1.53 & 2370 & $L$ \\
\hline$L_{3}$ & High(a) & Intermediate ${ }^{(b)}$ & Hairless(b) & $1 \cdot 42$ & 2440 & $L$ \\
\hline$L_{6}$ & $\operatorname{Low}^{(b)}$ & Short $(\mathrm{b})$ & Hairy(b) & $1 \cdot 34$ & 1050 & $S$ \\
\hline$L^{H}$ & $\mathrm{High}^{(\mathrm{b})}$ & Tall(b) & Hairy ${ }^{(b)}$ & $1 \cdot 47$ & 2570 & $L$ \\
\hline$S$ & Low $(a)$ & Short ${ }^{(a)}$ & Hairy $^{(\mathrm{c})}$ & $1 \cdot 32$ & 1430 & $\bar{S}$ \\
\hline$S_{3}$ & Low $^{(a)}$ & Short(b) & Hairy(b) & $1 \cdot 40$ & 1600 & $S$ \\
\hline$S_{6}$ & $\operatorname{Low}^{(b)}$ & Short ${ }^{(b)}$ & Hairy(b) & $1 \cdot 33$ & 1610 & $S$ \\
\hline$S^{h}$ & Low $^{(b)}$ & Intermediate ${ }^{(b)}$ & Hairless ${ }^{(b)}$ & $1 \cdot 36$ & 1570 & $L$ \\
\hline
\end{tabular}

(a) From Durrant (1971).

(b) Durrant (personal communication).

(c) Durrant and Nicholas (1970).

(d) Cullis (1976).

(e) There are differences in the absolute numbers of ribosomal RNA cistrons between those given by Timmis and Ingle $(1973,1975)$ and Cullis $(1975,1976)$ which is accounted for in terms of different estimates for the specific activity of the ribosomal RNA used in the hybridisations. If the values are given as a percentage of the number in $P l$ (100 per cent) then the two sets of data agree.

(f) Cullis and Kolodynska (1975).

need not necessarily be induced together, or even in the same direction under given induction conditions.

Crosses carried out between $L^{w h}$ and $S^{W H}$ have shown that there was an association between $W$ and small plant weight. Under one set of conditions there was no association between hairless septa and plant weight, while under a different set of growth conditions hairless septa and large plant weight were associated (Durrant, 1974). Thus, again the hairy septa can either be independent of plant weight determination, or be associated with it.

$L$ and $S$ had a 16 per cent nuclear DNA difference, $L^{H}$ and $S^{h}$ only a 10 per cent nuclear DNA difference while in another induction the difference between high and low DNA lines was 19 per cent (Evans, 1968a; Cullis, 1976; Durrant and Timmis, 1973). The attempt to induce genotrophs in 5 -inch pots gave only a 6 per cent DNA difference in the first generation and a zero difference in the next generation although plant weight differences 
of low magnitude were induced (Durrant and Jones, 1971). There is therefore a range of possible DNA differences in which the full plant weight differences could be obtained, but in all cases there was some DNA difference associated with the induction of the full plant weight change. The nuclear reversion lines did not necessarily show the association between plant weight difference and nuclear DNA difference. Lines $L_{3}$ and $S_{3}$ had the same nuclear DNA amounts but showed the full plant weight differences. However it has not been shown that the reversion in DNA in $L_{3}$ and $S_{3}$ has occurred at the same loci as those affected in the original induction. For example in the case of $S_{3}$, it is known that there has not been a total reversion of the ribosomal cistron number to the original value. Thus some DNA difference still survives in this reverted line. The minimum difference required to obtain the full plant weight differences has not been determined and it is possible that this difference was too small to be detected in measurements of total nuclear DNA amounts.

The ribosomal cistron number was associated with plant weight in as much as all the low plant weight lines have a reduced cistron number. This reduced value can be at two levels, one two-thirds of the other, so that a particular level of cistron number is not a sufficient character to determine plant weight. The high plant weight lines had the same number, or slightly fewer, ribosomal cistrons than the original variety so that there was no association here.

The peroxidase isozyme band patterns showed three basic patterns, one characteristic of $S$, one characteristic of $L$ and one characteristic of $P l$. The other lines, $L_{3}, L^{H}$ and $S^{h}$ showed the $L$ pattern, while $L_{6}, S_{3}$ and $S_{6}$ showed the $S$ pattern with a single band extra. Thus there was no association between plant weight and band pattern. However these groupings fell into the same height classes so there was an association between plant height and isozyme band pattern.

On the basis of the values given in table 1, each of the nine lines can be differentiated from any other by at least one character, the most similar being $S$ and $S_{6}$ which only have a slight difference in the isozyme band pattern.

This situation of each genotroph being unique when compared over a number of characters is also found in Nicotiana rustica, another species which is also susceptible to environmental induction (Hill, 1965; Towey and Jinks, 1976). If all the characters which have been measured on the 24 conditioned lines of $\mathcal{N}$. rustica maintained at Birmingham are taken into account, almost every line has a unique phenotype (Towey and Jinks, 1976).

\section{Possible mechanism of induction AND EXPREssion of IndUCED GHANGES}

A DNA difference has been observed between the extreme genotrophs, and these extremes behave as distinct genetic types. It is necessary to examine the relationship between the DNA changes and the other parameters to attempt to explain the induction by particular environments and the expression of the phenotypes of the genotrophs. The model proposed here to explain the phenotypic differences observed is based on the assumption that the changes are dependent on nuclear DNA differences between the genotrophs.

$38 / 2-\mathrm{B}$ 
A different model involving self-perpetuating regulatory cycles, and in which the DNA differences have no significance has previously been proposed (Bussey and Fieldes, 1974). The Bussey and Fieldes model assumes that the DNA changes are of secondary importance and possibly caused by a regulatory switch. Since each of the induced changes appears to be independent, at least six different regulatory cycles must exist. Further their scheme does not provide any explanation for the loss of plasticity in certain environments without any change in plant weight.

In a number of systems changes in DNA, usually, but not always, assoicated with development, have been described. Amphibian oocytes producc extra copies of the rRNA cistrons for use at a later stage of development (MacGregor, 1972). In maize, elements which do not have a fixed position in the chromosome but can be transposed to several locations have been described (this subject has been reviewed recently by Fincham and Shastry, 1974). The ribosomal RNA cistrons in Drosophila melanogaster are susceptible to both deletion and magnification. The magnified DNA may not be active in the generation during which magnification takes place (Ritossa, 1972).

The environmental induction of flax shows features which may be analogous to parts of all three systems mentioned above. The induction of extra copies of certain sequences occurs, although unlike the amphibian oocyte the extra DNA can be incorporated into the genome and inherited through many generations. It is possible that under particular conditions this extra DNA may be unstable and can be lost in nuclear reversion lines. The induction also appears to be a two-stage process involving first magnification or reduction and then stabilisation (Durrant and Jones, 1971). In the induction generation, the magnification or reduction of the DNA does not appear to affect the phenotype since there is not a correlation between plant weight and induction conditions. In fact, there appears to be an inverse correlation, $p$ treatment giving large plants under inducing conditions although the progeny from this treatment give the small genotroph, while the $n$ treatment gives small plants under induction but the progeny are the large genotroph.

The model for the induction of changes in DNA in flax proposed here requires the existence of two independent systems. The first is a mechanism by which specific regions of the DNA can be increased or decreased under inducing conditions. The second is a mechanism by which the number of copies in certain regions of homologous chromosomes can be monitored and can interact to increase or decrease the number of copies associated with one or both homologues.

In the first mechanism it is suggested here that insertion sequence (IS)elements may be involved. IS-elements are discrete DNA sequences of defined length between 800 and 1400 base pairs, that can participate in a variety of prokaryotic chromosomal rearrangements (see review by Starlinger 1976). By virtue of signals for gene expression carried by them, some ISelements exert distinct influences on the functions of genes in the vicinity of their location. Deletions and/or duplications can be induced by the integration of IS-elements. Deletions can occur in the region of the ISelement leaving the element intact. Three systems have been described in eukaryotes which resemble bacterial IS-elements.

(a) The controlling elements in maize. These elements do not have a fixed 
position within the chromosome but can be transposed to several locations. By transposition, these elements can exert their controlling influences on a number of genes. The excision of the element is not always exact so that deletions of various lengths can be formed which affect neighbouring genes (for review of literature see Fincham and Shastry, 1974).

(b) The "white-crimson" mutation in Drosophila melanogaster. Unstable mutations at the white locus of the $\mathrm{X}$ chromosome have been described by Green and his co-workers (Green, 1967; Rasmuson and Green, 1974). The mutations are interpreted as having been caused by the insertion of the DNA segment. This segment has the ability to be transposed with an adjacent functioning piece of the chromosome to another linkage group leaving a deletion in the $\mathrm{X}$ chromosome (Green, 1967; Rasmuson and Green, 1974).

(c) Mating-type instabilities in Schizosaccharomyces pombe. Certain mating-type instabilities can be interpreted in terms of transposition, and one of the mating-type genes involved is able to duplicate itself (see Starlinger 1976).

The second mechanism proposed for the interaction between homologous chromosomes is basically similar to that proposed for the magnification of ribosomal genes at the bobbed locus in Drosophila melanogaster (Ritossa, 1972). In certain combinations of chromosomes containing the bobbed locus, the number of rRNA cistrons at a particular bobbed locus could be changed, with either an increase or a decrease in the number (Ritossa, 1972; Graziani, Boncinelli, Malva and Gorgano, 1974; Locker, 1976). The efficiency of this change varied widely, that is, the rate of increase or decrease in the rRNA cistron number was not constant. The mangified rRNA cistrons did not appear to be active in the generation in which the increase took place, that is although the rRNA cistron number had increased, the expression of bobbed phenotype had not been changed in that generation. In the flax situation it is envisaged that the magnification or excision of particular sequences of the chromosome would occur in one generation, but the actual integration or loss of DNA would not occur until the sexual stage of that generation. The magnified DNA is envisaged as being inactive in the generation in which magnification occurs.

\section{(i) Model for environmental induction of $D \mathcal{N} A$ changes in flax}

Induction of $D \mathcal{N} A$ changes. The suggestion here is that the DNA changes are under the control of IS-elements. Two types of IS-elements are proposed, one which is susceptible to the physiological conditions caused by fertiliser induction conditions and the other susceptible to particular temperature conditions. Under the appropriate conditions the IS-elements, which are multiple elements occurring on different chromosomes, can be excised from the chromosome with an adjacent piece of DNA. After excision some form of recognition site remains at the location of the excised material. The excised material can be replicated with the chromosomal material but may not be synchronised with it, thus enabling differential replication to occur, with over-replication leading to an excess of DNA and under-replication leading to a deficiency of DNA (fig. 2, I). Differential replication of different sequences involved in induction could result in the under-replication of some sequences and the over-replication of other 


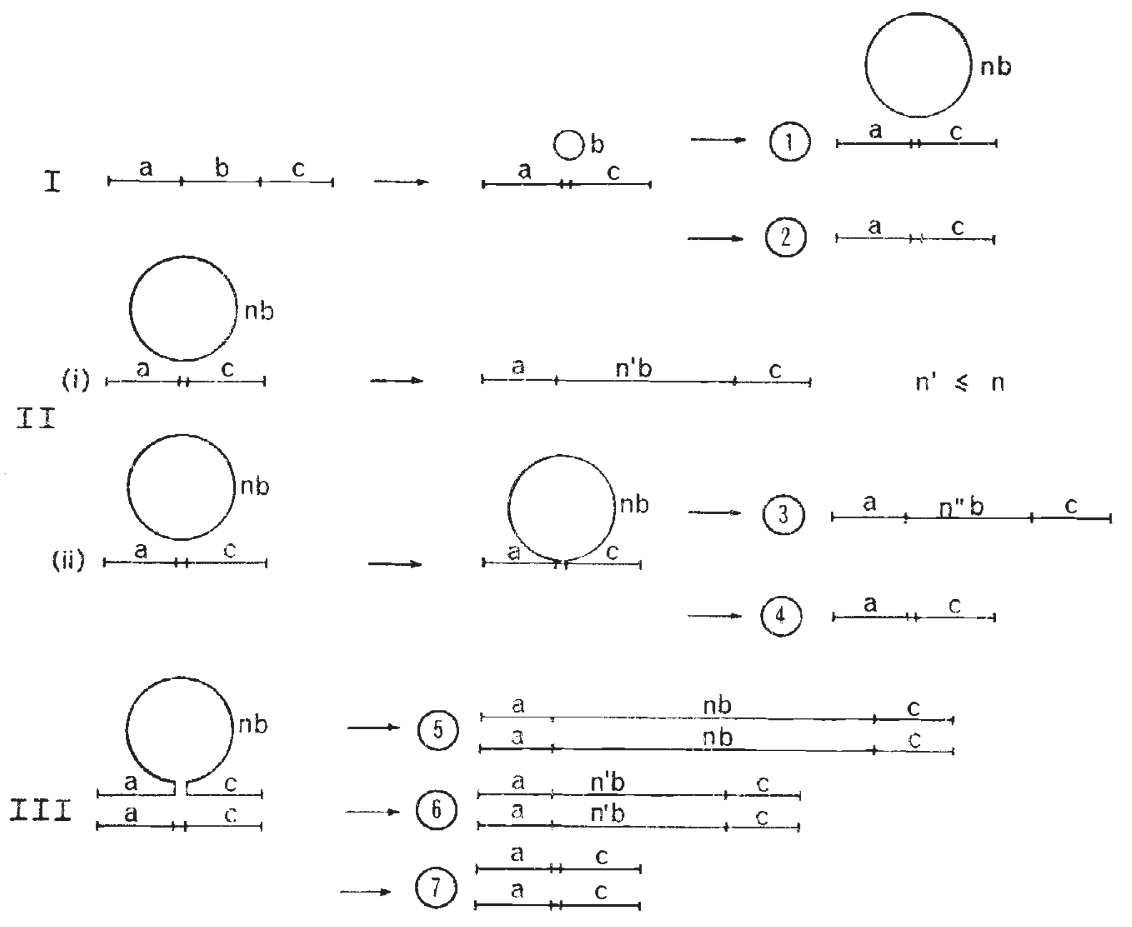

FiG. 2.-Model for change and stabilisation of DNA differences in environmental induction. $\mathrm{a}, \mathrm{b}, \mathrm{c}$ are three sequences on the same chromosome of which only b is susceptible to environmentally induced variation.

I. Induction. $\mathrm{a}, \mathrm{b}, \mathrm{c}$ in $P l$ condition. When $P l$ is germinated under inducing conditions $\mathrm{b}$ is excised leaving recognition site for reintegration. If conditions such that $\mathrm{b}$ is increased, e.g. $n$ treatment, get $\mathrm{I}$ (I) where $\mathrm{b}$ is increased many fold to give $n$ copies. If conditions are for loss of DNA then get I (2) with loss of DNA, giving $S$ genotroph.

II. Stabilisation. a and $\mathrm{c}$ plus many copies of $\mathrm{b}$ in the same nucleus after magnification. II (i) All or part of many copies of $b$ can be integrated at the previous site of $b$ giving $L$ genotroph. II (ii) The extra copies of b may become associated with a and c but not integrated. The growth conditions in the subsequent generation then determines whether (3) all or part of $b$ is integrated or (4) all of b is lost which is the situation found after induction in 5-inch pots with subsequent growth in pots or the field (see section 2 (iii)).

III. Variation of nuclear DNA content in crosses. For example in $L \times S$ any one of the following situations may occur:

(5) Increase in chromosome derived from $S$, which only contains a and c, to give both homologues with $\mathrm{n}$ copies of $\mathrm{b}$, which at this position are now both equivalent to the chromosome originally derived from $L$.

(6) Either unequal crossing-over or a monitored change in the number of copies to give equal numbers of copies of $\mathrm{b}$ on each chromosome. The number of copies on each chromosome may not be equal to half that originally present on the $L$ homologue as some copies may be excised during the unequal crossing-over or monitoring stage, or (7) Excision of all copies of b from chromosome derived from $L$.

$((5),(6)$ and (7) are the situations envisaged in the control of the hairy septa character described in section 7 (iv).) 
sequences within the same nucleus. The total change in DNA would not be due simply to a change in the number of IS-sequences as it would require $1 \cdot 4 \times 10^{4}$ extra copies of a sequence 1000 nucleotides long to give a 10 per cent DNA difference in flax.

Stabilisation of $D \mathcal{N} A$ changes. When the sexual stage of the life cycle was reached one or many copies of particular sequences may have been reintegrated and this generated the stable DNA differences between lines (fig. 2, II). The number of copies, and the position of the integration of these copies would affect the expression of parts of the flax genome.

Variation of DNA amounts in crosses. When different numbers of copies of a sequence at a particular locus on homologous chromosomes are brought together in a single nucleus they may interact so that the number of copies is modified on one or both homologues (fig. 2, III). The direction of this modification, whether there is a change in both homologues to an intermediate value, or a change in only one homologue to approach the value of the other will determine the phenotypic change observed. This process may be analogous to the modification of the bobbed locus in Drosophila melanogaster described earlier.

\section{(ii) Control of expression of induced characters by $D \mathcal{N A}$ changes}

It has been suggested that the difference between the plant weights of the large and small genotrophs is determined by the ribosomal RNA cistron number difference (Timmis and Ingle, 1973, 1975) in a manner analogous to the suggested reduction in vigour of the bobbed mutants in Drosophila melanogaster (Ritossa and Scala, 1969). The suggestion that the small type may be due to a limitation of some product is supported by the different responses of $L$ and $S$ to their growth environment. $L$ can take advantage of a good environment to produce a plant up to six times the weight of $S$, while under poor growth conditions $L$ and $S$ are approximately the same size (Durrant, 1971). However, since $L$ and $P l$ have similar ribosomal cistron numbers but different plant weights (under the appropriate growth conditions) and $L_{6}$ and $S_{6}$ have similar plant weights but different rRNA cistron numbers, plant weight differences cannot be determined solely by differences in rRNA cistron number. All the small lines do have a reduced rRNA cistron number so the ability to produce rRNA may have some effect on the final plant weight. Givens and Phillips (1973) suggested that in maize not all the rRNA cistrons were active. If this was the case in $P l$, then the plant weight differences may be generated by a combination of rRNA cistron number and activity differences.

The DNA difference between $L$ and $S$ has been shown to be due to the production of sequences of intermediate repetition (Cullis, 1973, 1975). Some of these sequences could be involved in the regulation of the septa hairyness with the number of additional copies present affecting the level of expression of this character. The number present in $L$ would cause the change to hairlessness, with numbers of copies between those in $L$ and either $P l$ or $S$ causing different levels of expression to produce classes I, II and III of intermediate hair number.

The instability of the hairy septa character in crosses between $L$ and $S$ shows a number of features similar to those observed in the modification of the bobbed locus in Drosophila melanogaster. In certain combinations of 
chromosomes containing the bobbed locus, the number of rRNA cistrons at a particular bobbed locus could be modified, with either an increase or decrease in the number (Ritossa, 1972; Graziani et al., 1974; Locker, 1976). The efficiency of this modification, that is the number by which the rRNA cistrons changed, varied widely. The modified locus was not immediately stable and could be further modified, depending on the number of rRNA cistrons on its homologue with which it was combined in the next generation. The degree of instability decreased with successive generations, with much less instability being observed in the fourth generation than the second.

In flax genotrophs when the two extremes of numbers of sequences found in $L$ and $S$ are combined in the same nucleus, instability may occur with interaction between the chromosomes resulting in either an increase or a decrease in the number of copies of the sequences (fig. 2, III). This would be a change in the number of copies of particular sequences, which may or may not have an associated IS-element, in a particular region of the chromosome. The variation in the number of copies could occur over a number of generations with the balance finally achieved depending on the number of copies of the particular sequence that were present on each chromosome when they were combined in the same nucleus.

The changes in isozyme band pattern could also be explained in terms of gene dosage effects. Dosage effects, when the isozyme band pattern depends on the number of copies of a gene present, have been demonstrated in polyploid and aneuploid lines of barley (McDaniel and Ramage, 1970) various Pisum species (Matthews and Williams, 1974), Datura stramonium (Carlson, 1972) and Drosophila (Rawls and Lucchesi, 1974). Changes in the number of copies can cause the appearance of additional bands, loss of bands, increase or decrease in activity of all or some of the isozymes and altered mobility of selected bands. All of these situations have been observed to occur in the isozyme patterns of $L, S$ and $P l$ types, so that these changes may be due to gene dosage effects.

The nuclear reversion types in which the nuclear DNA difference disappears with no change in certain other characteristics requires explanation. There are at least two possibilities:

(a) The amount of DNA difference required for the expression of the phenotypic differences observed in the reversion types was sufficiently small to be undetectable by Feulgen cytophotometry. In this case, the DNA changed during reversion was at the same loci as those involved in the original induction, with the DNA sequences involved in the control of the characters studied being preferentially stabilised.

(b) The change in the DNA, by growth out of doors (which was equivalent to growth at a lower temperature) occurred at loci not involved in the original induction. Evidence for this possibility has been obtained, since the small type obtained by temperature effects (growth at $19^{\circ} \mathrm{C} / 11^{\circ} \mathrm{C}$ day/night temperature) was shown to be different to the small type obtained by fertiliser treatment (Durrant, 1971).

The possibilities $(a)$ and $(b)$ could be distinguished by a characterisation of the DNA of the nuclear reversion types, as they give different predictions. In $(a)$ the DNA from reversion types should be virtually indistinguishable from the original variety while $(b)$ predicts that some, if not all of the intermediate sequences should still be present in the DNA of the reversion types. 


\section{Conclusion}

The proposed model can account for the observed events in the environmental induction of flax and certain predictions from the model are experimentally testable. It should be possible to determine whether there was any instability in the rDNA in crosses between $L$ and $S$. The explanation of the instability, in crosses between genotrophs, of plant weight and hairy septa has been in terms of the change in the number of copies of particular sequences in the hybrid nucleus. With the rDNA it would be possible to measure the number of copies of this particular sequence in crosses and to determine its mode of inheritance.

The mechanism proposed for the formation of nuclear reversion types involves sequences of DNA not involved in the original induction. There should be detectable differences in the DNA of large and small types which have the same nuclear DNA amounts, depending whether they are derived from an $L$ or an $S$ line. The $L$ and $S$ lines should also be capable of induction by different temperature régimes if temperature can act as an inducing agent and can be independent of the fertiliser treatments. Induction of changes in $L$ and $S$ under different temperature/light régimes would give further information on the environments in which all the characters susceptible to induction are stable.

IS-elements should be detectable in the DNA from flax plants. Selfduplicating segments of DNA containing IS-elements should be detectable in plastic types growing under inducing conditions. Some of these possibilities are currently being investigated in this laboratory.

\section{Appendix}

This section has been included to list the flax lines and their derivation, and to provide compact explanations of terms as they are used in this review. The order is logical rather than alphabetical.

Genotroph. An environmentally induced line, which is distinguishable phenotypically from the line from which it was induced, and which appears to be a distinct genetic type.

Plasticity. The ability to respond to environmental conditioning to produce different stable genotrophs. The plastic type is denoted $\mathrm{Pl}$.

Large genotroph (L) and small genotroph $(\mathrm{S})$. The extreme types with regard to plant weight obtained from the induction of $P l$ by fertiliser treatments $n$ and $p$ respectively. Where $L$ and $S$ are used without sub- or super-scripts they refer to two lines which have approximately a six-fold plant weight difference, 16 per cent nuclear DNA difference, $L$ has a hairless septa and $S$ hairy septa. When genotrophs are referred to as large or small this only implies a plant weight difference with no necessary correlations with other characters.

Inducing environment. One in which the $P l$ type is changed into a stable genotroph.

Non-inducing environment. One in which the $P l$ type is not changed into a stable genotroph and remains plastic.

Genotrophs referred to in this review

$L$ and $S$ have been described above. 
Nuclear reversion types

$L_{3}$-obtained from $L$ by growth totally out of doors for 3 generations. It is the same as $L$ phenotypically but has a lower nuclear DNA amount than $L$, with an amount approximately the same as that in $\mathrm{Pl}$.

$L_{6}$-obtained from $L_{3}$ by a further 3 generations growth out of doors. It is phenotypically the same as $S$ in plant weight, height, hairyness of capsule septa and nuclear DNA content i.e. has changed from a large genotroph to a small genotroph.

$S_{3}$-obtained from $S$ by growth out of doors for 3 generations. It is still phenotypically the same as $S$ but has more nuclear DNA than $S$ (approximately the same amount as $L_{3}$ and $P l$ ).

$S_{6}$-obtained from $S_{3}$ by growth out of doors for 3 generations and is phenotypically the same as $S$ with the same nuclear DNA amount as $S$.

Large and small types induced in a separate induction experiment from $\mathrm{L}$ and $\mathrm{S}$ $L^{H}$-a large genotroph induced by $n$ treatment in 1961 which has more nuclear DNA than $P l$, but less than $L$, has hairy septa and is taller than $L$. The nuclear DNA diffcrences between $L^{H}$ and $S^{h}$ is approximately 10 per cent.

$S^{h}$-a small genotroph by $p$ treatment in 1961 ; it has a similar nuclear DNA amount to $S$, is taller than $S$ and has hairless septa. table 1 .

The full characteristics of the nine genotrophs considered are given in

Acknowledgments.-I would like to thank Dr A. Durrant who provided the sced of the genotrophs for work done in this laboratory and also for unpublished information, Miss P. Towey for a preprint and Professor D. R. Davies and Dr C. L. Hedley for critically reading the manuscript.

\section{REFERENCES}

BRITten, R. J., AND kOHNE, D. E. 1968. Repeated sequences in DNA. Science, 161, 529-540. BUSSEY, H., AND FIELDES, M. A. 1974. A model for the stably inherited environmentally induced changes in plants. Nature, 251, 708-709.

CARIsON, P. s. 1972. Locating gene loci with aneuploids. Mol. Gen. Genet., 114, 273280.

GULlIs, C. A. 1973. DNA differences between flax genotrophs. Nature, 243, 515-516.

cullis, c. A. 1975. Environmentally induced DNA differences in flax. In Modification of the Information Content of Plant Cells, ed. R. Markham, D. R. Davies, D. A. Hopwood and W. R. Horne, pp. 27-36. North Holland, Amsterdam.

CULLIS, C. A. 1976. Environmentally induced changes in ribosomal RNA cistron number in flax. Heredity, 36, 73-79.

CULlis, C. A., AND KOLODYNSKA, K. 1975. Variations in the isozymes of flax genotrophs. Biochem. Genetics, 13, 687-697.

dillman, A. s. 1936. Improvement in flax. U.S. Dept. Agric. Yearbook, 745-784.

DURRANT, A. 1958. Environmental conditioning of flax. Nature, 181, 928-929.

DURrant, A. 1962a. The environmental induction of heritable changes in Linum. Heredity, $17,27-61$.

DURRANT, A. 1962b. Induction, reversion and epitrophism of flax genotrophs. Nature, $196,1302-1304$.

DURRANT, A. 1971. Induction and growth of flax genotrophs. Heredity, 27, 277-298.

DURRANT, A. 1972. Studies on reversion of induced plant weight changes in flax by outcrossing. Heredity, 29, 71-81.

DURRANT, A. 1974. The association of induced changes in flax. Heredity, 32, 133-143.

DURRANT, A., AND JONES, T. W. A. 1971. Reversion of the induced changes in amount of DNA in Linum. Heredity, 27, 431-439. 
DURRAnt, A., AND Nicholas, D. B. 1970. An unstable gene in flax. Heredity, 25, 513-527. DURRANT, A., AND TIMMIs, J. N. 1973. Genetic control of environmentally induced changes in Linum. Heredity, 30, 369-379.

DURRANT, A., AND TYSON, H. 1964. A diallel cross of genotypes and genotrophs of Linum. Heredity, 19, 207-227.

Evans, G. M. 1968a. Nuclear changes in flax. Heredity, 23, 25-38.

EVANS, G. M. 1968b. Induced chromosomal changes in Linum. Heredity, 23, 301-310.

EVANS, G. M., DURRANT, A., AND REEs, H. 1966. Associated nuclear changes in the induction of flax genotrophs. Nature, 212, 697-699.

FIELDES, M. A., AND Tyson, H. 1972. Activity and relative mobility of peroxidase isozymes in genotrophs and genotypes of flax (Linum usitatissimum). Can. 7. Genet. Cytol., 14, 625-636.

FIELDES, M. A., AND TYSON, H. 1973a. Activity and relative mobility of peroxidase and esterase isozymes of flax (Linum usitatissimum) genotrophs. I. Developing main stems. Can. 7. Genet. Cytol., 15, 731-744.

fieldes, M. A., AND tyson, H. 1973b. Activity and relative mobility of peroxidase and esterase isozymes of flax (Linum usitatissimum) genotrophs. II. F1 hybrids and nuclear DNA reversion types. Can. 7. Genet. Cytol., 15, 745-755.

FIELDES, M. A., TYSON, H., AND BASHOUR, N. 1976. Relative shifts in mobility in anionic peroxidase isozymes between stem base and apex of flax genotrophs. Phytochem., 15, 247-250.

Fincham, J. R. S., AND shastry, G. R. к. 1974. Controlling elements in maize. Ann. Rev. Genet., 8, 15-50.

GALSTON, A. W., BONNER, H., AND BAKER, R. s. 1953. Flavoprotein and peroxidase as components of the indole acetic acid oxidase system of peas. Arch. Biochem. Biophys., $42,456-470$.

GIVENS, J. F., AND PHILlips, R. L. 1973. Localisation and estimation of the number of active versus inactive rDNA cistrons within the nuclear organiser region in $Z$ ea mays. Genetics, 74, suppl. 2, 94.

GRAZIANi, F., BONCINElli, E., MALVA, C., AND GoRgANo, s. 1974. Mutual regulation of magnified bobbed loci in Drosophila melanogaster. Molec. Gen. Genet., 134, 307-311.

GREeN, M. M. 1967. The genetics of a mutable gene at the white locus of D. melanogaster. Genetics, 56, 467-482.

HILL, J. 1965. Environmental induction of heritable changes in Nicotiana rustica. Nature, $207,732-734$.

ingle, J., PEArson, G. G., AND sinclair, J. 1973. Species distribution and properties of nuclear satellite DNA in higher plants. Nature, 242, 193-197.

JOARDER, I. O., AL-SAHEAL, Y., BEGUM, J., AND DURRANT, A. 1975. Environments inducing changes in amount of DNA in flax. Heredity, 34, 247-253.

LOCKER, D. 1976. Instability at the bobbed locus following magnification in Drosophila melanogaster. Molec. Gen. Genet., 143, 261-268.

MACGREgOR, H. c. 1972. The nucleolus and its genes in amphibian oogenesis. Biol. Rev., $47,177-210$.

MCDANIEL, R. G., AND RAMAGE, P. T. 1970. Genetics of a primary trisomic series in barley: Identification by protein electrophoresis. Can. F. Genet. Cytol., 12, 490-495.

MCLELLAN, J. C., AND DURRANT, A. 1973. Instability of Hh heterozygotes in flax genotrophs. Heredity, 30, 63-71.

MATTHEWS, P., AND Williams, H. 1974. Isozyme profiles of diploid and autotetraploid pea plants. Fohn Innes Annual Report 1973.

RASMUSON, B., AND GREen, M. M. 1974. Genetic instability in D. melanogaster. Evidence for insertion mutations. Molec. Gen. Genetics., 133, 237-247.

RAWLS, J. M., AND LucchesI, J. C. 1974. Regulation of enzyme activities in Drosophila. I. The deletion of regulatory loci by gene dosage responses. Genet. Res., 24, 59-72.

RITOSSA, F. 1972. Procedure for magnification of lethal deletions of genes for ribosomal RNA. Nature New Biology, 240, 109-111.

RITOSSA, F. M., AND SCALA, G. 1969. Equilibrium variation in the redundancy of rDNA in Drosophila melanogaster. Genet. Suppl., 61, 305-318.

starlinger, P. 1976. IS-elements in microorganisms. Current topics in Microbiology and Immunology (in press).

tammes, т. 1928. The genetics of the genus Linum. Bibliog. Genetica, 4, 1-36.

Timmis, J. N., AND INGLE, J. 1973. Environmentally induced changes in rRNA gene redundancy. Nature Nero Biol., 244, 235-236. 
TIMmIs, J. N., AND INGLE, J. 1974. The nature of the variable DNA associated with environmental induction in flax. Heredity, 33, 339-346.

TIMMrs, J. N., AND INGLE, J. 1975. The status of ribosomal RNA genes during nuclear DNA reversion in flax. Biochem. Genet., 13, 629-634.

TOWEY, P., AND JINKs, J. L. 1976. The number of phenotypes among the conditioned lines of Nicotiana rustica. Heredity 37, 357-364. 